\title{
Surface Modification Resists Using Photoacid and Photobase Generating Polymers
}

\author{
Masamitsu Shirai, Hideki Nakaseko and Masahiro Tsunooka \\ Department of Applied Chemistry, Graduate School of Engineering, \\ Osaka Prefecture University, Sakai, Osaka 599-8531, Japan
}

Keywords: surface imaging, photoacid generator, photobase generator, dry development

\section{Introduction}

Surface imaging process is an important technology for ArF or VUV lithography. We have studied the plasma developable photoresist systems based on the acid catalyzed polysiloxane formation at the irradiated or unirradiated film surface by a chemical vapor deposition (CVD) method using vapor of alkoxysilanes.[1-4] When photoacid generating polymers were used, negative-tone images were obtained by the surface modification process and followed by dry etching. In our recent study, we have devised a new surface modification system using polymers having photobase generating units and thermally decomposable sulfonic acid ester units in the same polymer chain. [5] This system gave positive-tone images by a surface modification technique after irradiation and followed by post-exposure bake treatments. However, one problem was the difficulty of control of baking temperature and baking period because the diffusion rate of the acids generated photochemically in the film is very sensitive to those factors. In this study, to eliminate the problem, we have devised a new surface modification system using polymers bearing both photobase generating units and photoacid generating units. The methodology of the present system is shown in Scheme 1. In this system irradiation with a mask was first carried out with 146 or $193 \mathrm{~nm}$ light and then flood irradiation was done with $254 \mathrm{~nm}$ light. Although amines can be generated by 146 or $193 \mathrm{~nm}$ light, no amines were generated by $254 \mathrm{~nm}$ light. Thus, after surface modification treatment with alkoxysilane vapor, a positivetone image can be obtained by the etching with an oxygen plasma.

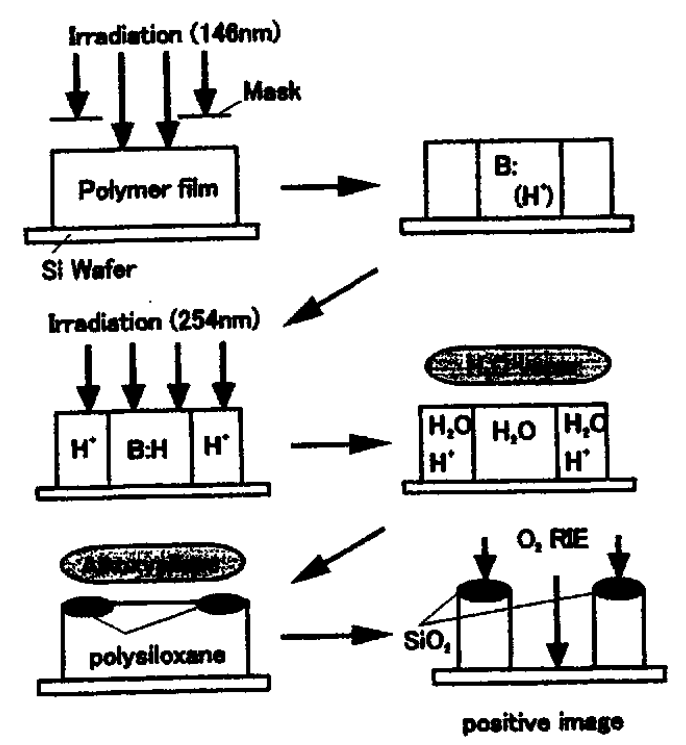

Scheme 1

\section{Experimental}

2.1 Materials

2.1.1 Preparation of monomers

O-Acryloyl acetone oxime (AAO) was freshly synthesized. Acetoxime $(11.0 \mathrm{~g})$, $\mathrm{CH}_{2} \mathrm{Cl}_{2}(250 \mathrm{ml})$ and triethylamine $(33.0 \mathrm{ml})$ were placed in a four-neck round-bottom flask. Acryloyl chloride ( $13.6 \mathrm{~g}$ ) was slowly added at 5 ${ }^{\circ} \mathrm{C}$. After addition the reaction was continued at room temperature for $3 \mathrm{~h}$. The reaction mixture was poured into ice-cold $5 \% \mathrm{HCl}$. The $\mathrm{CH}_{2} \mathrm{Cl}_{2}$ 
Table 1. Polymerization conditions and characteristics of polymers

\begin{tabular}{lcccccc}
\hline \multirow{2}{*}{ Polymer } & \multicolumn{3}{c}{$\begin{array}{c}\text { Composition in polymer } \\
\text { (mol\%) }\end{array}$} & Mn & Mw/Mn & $\mathrm{T}_{\mathrm{d}}\left({ }^{\circ} \mathrm{C}\right)$ \\
\cline { 2 - 5 } & $\mathrm{X}$ & $\mathrm{Y}$ & $\mathrm{Z}$ & & & \\
\hline AAO(51)-MMA(49) & 51 & 0 & 49 & 2.1 & 3.6 & 64.5 \\
AAO(54)-NIS(16)-MMA(30) & 54 & 16 & 30 & 4.1 & 3.0 & 76.4 \\
CAM(47)-MMA(53) & 47 & 0 & 53 & 7.2 & 1.8 & - b) \\
CAM(33)-NIS(23)-MMA(44) & 33 & 23 & 44 & 17.2 & 13.2 & 135 \\
\hline
\end{tabular}

a) See Scheme 1. b) Not measured.<smiles>[X]C(C)(CCc1ccc(S(=O)(=O)OC2=CCCc3ccccc32)cc1)CC(C)(C)CC(C)(C)C(=O)OC</smiles>

Scheme 2

layer was thoroughly washed with water, $5 \% \mathrm{NaHCO}_{3}$, and water. The $\mathrm{CH}_{2} \mathrm{Cl}_{2}$ layer was dried with anhydrous $\mathrm{Na}_{2} \mathrm{SO}_{4}$. After filtration the $\mathrm{CH}_{2} \mathrm{Cl}_{2}$ was evaporated and the residue was purified by vacuum distillation: bp $41.5^{\circ} \mathrm{Cl}$ $4 \mathrm{mmHg}$, yield $32 \%$. 1H-NMR $\left(\mathrm{CDCl}_{3}\right): \delta 2.1$ (d, $6 \mathrm{H}), 5.9(\mathrm{~d}, 1 \mathrm{H}), 6.2(\mathrm{dd}, 1 \mathrm{H}), 6.5(\mathrm{~d}, 1 \mathrm{H})$.

C a m p he n y 1 i de $n$ e i m i no acryloyloxyethylcarbamate (CAM) was prepared from camphor oxime and methacryloyloxyethylisocyanate. Camphor oxime $(2.0 \mathrm{~g})$ was dissolved in $\mathrm{CH}_{2} \mathrm{Cl}_{2}(25 \mathrm{ml})$ and methacryloyloxyethylisocyanate $(2.0 \mathrm{~g})$ was slowly added. Catalytic amounts of dibutyltin dilaurate were added and the reaction mixture was stirred at room temperature for $72 \mathrm{~h}$. After removing the solvent, the product was extracted with hot n-hexane. The crude product was purified by recrystallization from $\mathrm{n}$-hexane: $\mathrm{mp}$ $113-114^{\circ} \mathrm{C}$, yield $56 \%$. $1 \mathrm{H}-\mathrm{NMR}\left(\mathrm{CDCl}_{3}\right): \delta 0.8$ $(\mathrm{s}, 3 \mathrm{H}), 0.9(\mathrm{~s}, 3 \mathrm{H}), 1.0(\mathrm{~s}, 3 \mathrm{H}), 1.2-2.7(\mathrm{~m}, 10 \mathrm{H})$, $3.6(\mathrm{dd}, 2 \mathrm{H}), 4.3(\mathrm{dd}, 2 \mathrm{H}), 5.6(\mathrm{~s}, 1 \mathrm{H}), 6.1(\mathrm{~s}$, $1 \mathrm{H}), 6.6(\mathrm{~s}, 1 \mathrm{H})$.

1,2,3,4-Tetrahydro-1-naphthylideneimino pstyrenesulfonate (NIS) was prepared according to the reported method. [6]

\subsubsection{Preparation of polymers}

The terpolymer of AAO, NIS and MMA and the copolymer of AAO and MMA were prepared by the photopolymerization using azobisisobutyronitrile (AIBN) as an initiator at $30^{\circ} \mathrm{C}$. A high-pressure $\mathrm{Hg} \operatorname{lamp}(\lambda>350 \mathrm{~nm})$ was used. The terpolymer of CAM, NIS and MMA and the copolymer of CAM and MMA were prepared by the conventional radical polymerization using AIBN at $55^{\circ} \mathrm{C}$. Characteristics of the polymers are shown in Table 1 and polymer structures are shown in Scheme 2.

\subsection{Method}

Polymer films were prepared by casting cyclohexanone solutions of the polymers onto quartz plate or silicon wafer. A low-pressure $\mathrm{Hg}$ lamp was used for $254 \mathrm{~nm}$ irradiation in air and a $\mathrm{Kr}_{2}$ excimer lamp (Ushio UER20H-146V, light intensity: $3 \mathrm{~mW} / \mathrm{cm}^{2}$ ) was used for $146 \mathrm{~nm}$ irradiation under nitrogen atmosphere. The surface modification of the films was carried out by exposing the films to the vapor of alkoxysilanes at $30{ }^{\circ} \mathrm{C}$. Amounts of polysiloxanes generated at the film surface were measured by FT-IR spectroscopy.

Oxygen plasma etching was carried out at room temperature using laboratory-constructed 


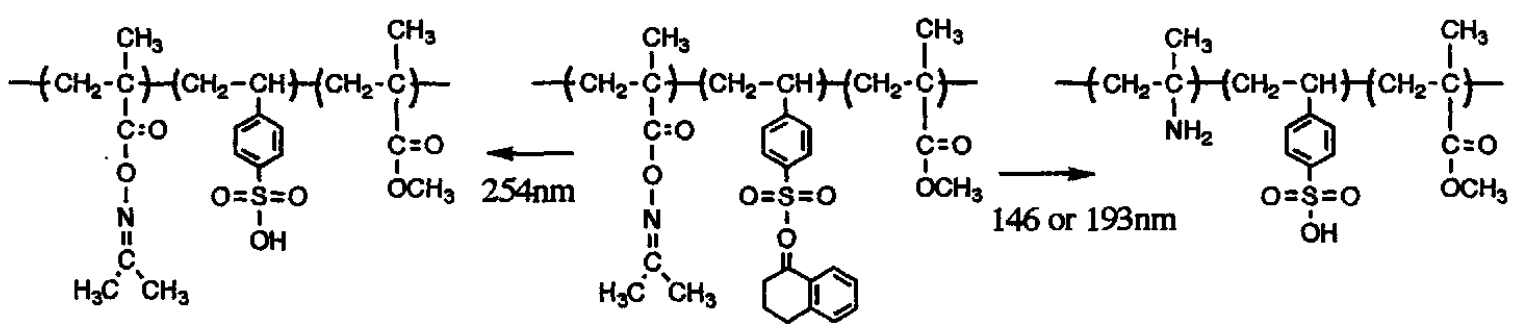

\section{Scheme 3}

apparatus where the oxygen plasma was generated using two parallel electrodes and $\mathrm{RF}$ power supplies. The typical etching conditions were as follows: $20 \mathrm{~W}$ power $(13.56 \mathrm{MHz})$, power density of $1.0 \mathrm{~W} / \mathrm{cm}^{2}, 80 \mathrm{mTorr}$, and oxygen flow of $1.0 \mathrm{sccm}$.

\section{Results and Discussion}

It was reported that some esters of carboxylic acids and oximes (acyloxime) were photolyzed to generate amines together with the formation of $\mathrm{CO}_{2}$ and ketones. [7] The oxime carbamates were also reported to be photolyzed to generate amines.[8] On the other hand, some esters of sulfonic acids and oximes (imino sulfonate) can be photolyzed to generate sulfonic acids. [9] When the polymers were irradiated at $146 \mathrm{~nm}$, the photolysis of the AAO, CAM and NIS units in the polymers were confirmed by FT-IR and UV spectroscopies. When these polymers were irradiated with $254 \mathrm{~nm}$ light, only NIS units were photolyzed (Scheme 3). The AAO and CAM units were stable to $254 \mathrm{~nm}$ irradiation because those units did not absorb the light at $254 \mathrm{~nm}$.

The surface modification of irradiated films were performed by exposing the films to the vapor of methyltriethoxysilane (MTEOS) at $30^{\circ} \mathrm{C}$. Polysiloxane networks were generated at the areas where the photochemically generated sulfonic acids existed. The amounts of polysiloxanes were measured by FT-IR spectroscopy using the absorbance at $1121 \mathrm{~cm}^{-1}$ due to O-Si-O . When the film s of $\mathrm{AAO}(54)-$ NIS(16)-MMA(30) and CAM(33)-NIS(23)MMA(44) were irradiated with $254 \mathrm{~nm}$ light and subsequently exposed to the vapor of MTEOS, the amounts of polysiloxanes at the film surface increased with irradiation time (Fig. 1). The sensitivity of the AAO(54)-NIS(16)-MMA(30) film was slightly higher than the CAM(33)NIS(23)-MMA(44) film.

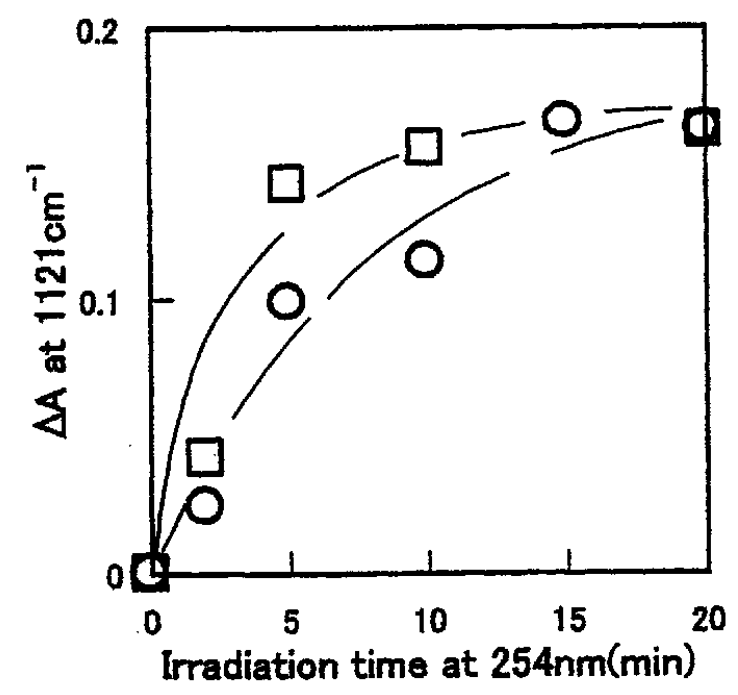

Fig. 1. Polysiloxane formation at the film surface irradiated at $254 \mathrm{~nm}$.

CVD treatment: 10 min with MTEOS.

Polymer: ( $\square$ ) AAO(54)-NIS(16)-MMA(30),

(O) CAM(33)-NIS(23)-MMA(44).

Fig. 2 shows the effect of irradiation with 146 and $254 \mathrm{~nm}$ light on the polysiloxane formation at the AAO(54)-NIS(16)-MMA(30) film surface. The sample films were first irradiated at $146 \mathrm{~nm}$ light for a given period. The strongly reduced formation of polysiloxanes was observed for the sample films irradiated at $146 \mathrm{~nm}$. This is due to the formation of amines which can neutralize sulfonic acids formed by flood irradiation with $254 \mathrm{~nm}$ light. A similar result was obtained for the CAM(33)-NIS(23)MMA(44) film. These findings suggest that the present system can be used for positive-type imaging system because the film modified with polysiloxane showed high resistance to the etching with an oxygen plasma. 


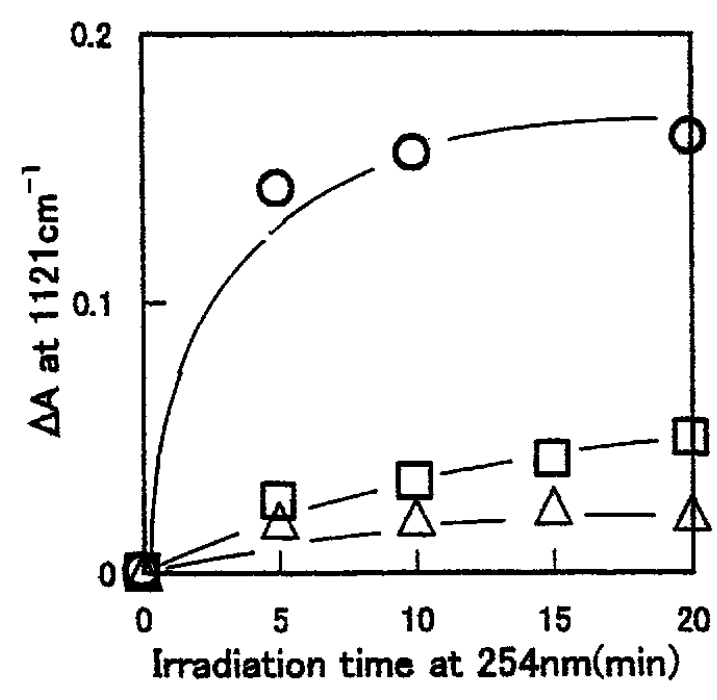

Fig. 2. Polysiloxane formation at the AAO(54)-NIS(16)-MMA(30) film surface preirradiated at $146 \mathrm{~nm}$.

CVD treatment: 10 min with MTEOS. Preirradiation time with $146 \mathrm{~nm}$ light:

(O) $0,(\square) 30,(\triangle) 60 \mathrm{sec}$.

Fig. 3 shows the SEM photographs of positive-tone images obtained by using present system. Using ArF lithography $0.13 \mu \mathrm{m} \mathrm{L/S}$ images were obtained. In this case the AAO(54)-NIS(16)-MMA(30) film was first irradiated at $193 \mathrm{~nm}\left(98 \mathrm{~mJ} / \mathrm{cm}^{2}\right)$ and then irradiated at $254 \mathrm{~nm}\left(6 \mathrm{~mJ} / \mathrm{cm}^{2}\right)$. The irradiated sample was exposed to the vapor of MTEOS for $10 \mathrm{~min}$ at relative humidity of $100 \%$. The etching was performed by oxygen plasma using a laboratory-constructed apparatus.
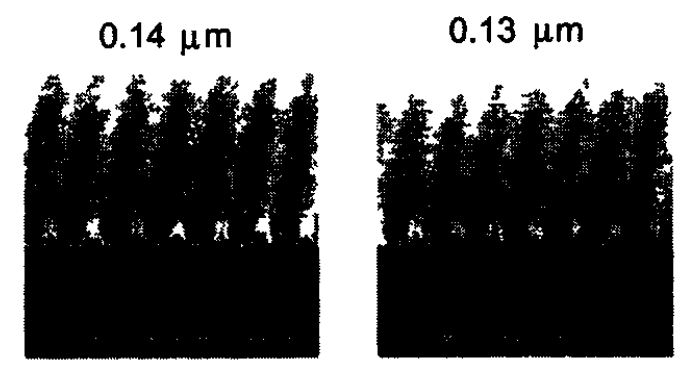

Fig. 3 SEM photographs of positive images.

\section{Conclusion}

Polymers having photobase generating units and photoacid generating units were used as the surface modification resists. The patterned exposure with $193 \mathrm{~nm}$ light was first done and then the flood exposure with $254 \mathrm{~nm}$ light was carried out. The irradiated sample treated with alkoxysilane vapor was developed with an oxygen plasma and positive-tone images were obtained.

\section{Acknowledgment}

This work was partially supported by a Grantin-Aid for Scientific Research (C) No. 11650912 from Japan Society for the Promotion of Science. The authors also acknowledge the financial support from the Casio Science Promotion Foundation.

\section{References}

1. M. Shirai, J. Nakanishi, M. Tsunooka, T. Matsuo and M. Endo, J. Photopolym. Sci. Technol., 11 (1998) 641.

2. T. Matsuo, M. Endo, S. Mori, K. Kuhara, M. Sasago, M. Shirai and M. Tsunooka, $J$. Photopolym. Sci. Technol., 11 (1998) 645. 3. M. Shirai, S. Umeda, M. Tsunooka and T. Matsuo, Eur. Polym. J., 34 (1998) 1295. 4. T. Matsuo, M. Endo, M. Shirai and M. Tsunooka, J. Electrochem. Soc., 144 (1997) 2903.

5. M. Shirai, M. Endo, M. Tsunooka and M. Endo, J. Photopolym. Sci. Technol., 12 (1999) 669.

6. M. Shirai, M. Hayashi and M. Tsunooka, Macromolecules, 25 (1992) 195.

7. K. Ito, Y. Shigeru, Y. Kawata, K. Ito and M. Tsunooka, Can. J. Chem., 73 (1995) 1924.

8. G. Bucher, J. C. Scaiano, R. Sinta, G. Barclay and J. Cameron, J. Am. Chem. Soc., 117 (1995) 3848.

9. M. Shirai, K. Kinoshita and M. Tsunooka, Eur. Polym. J., 28 (1992) 379. 